\title{
Current Status of Small/Micro Hydropower in Nepal: A Case Study of Giringdi SHP
}

\author{
Saurabh Agrawal 1,2, *, Roshan Pandey ${ }^{1,2}$ \\ ${ }^{1}$ Department of Mechanical Engineering, Institute of Engineering, Tribhuvan University, Nepal \\ ${ }^{2}$ Faculty of Technology, Nepal Academy of Science and Technology, Nepal \\ Corresponding Email: saurabh.agraw143@gmail.com
}

\begin{abstract}
:
Nepal has economically exploitable hydropower potential of about 42,000 Megawatts out of which only about 2\% has been harnessed so far. Nepal's average annual per capita electricity consumption is about $161 \mathrm{kWh}$ - one of the lowest consumptions in South Asia. Electrical energy available for the fiscal year 2016/2017 was $6257 \mathrm{GWh}$, of which NEA's own contribution was only $36.84 \%$ whereas those imported from India and local IPPs accounted for $34.76 \%$ and $28.40 \%$ respectively. Despite its vast hydropower potential, Nepal suffers from severe and long-lasting electricity supply crisis. The main objective of the study was to assess the current status of small/micro hydropower in Nepal through a case study of Giringdi SHP $(75 \mathrm{~kW})$, considered as an example of excellence in small/micro hydropower. Analysis was done based on the primary data that was accumulated via questionnaires, simple observation, and direct on-site testing of components. It was found that the condition of plant with regard to installed major equipment like turbine, generator, Electronic Load Controller (ELC), control valves, panel board and other electrical parameters were only satisfactory while the working condition of other components like bearings, shaft and couplings were considerably poor. Even the condition of one of the best sites, seemed to be satisfactory reflecting the frequency of maintenance and policies in rural off-grid/not connected region. Thus, this all shows that the government policy for off grid/ not connection in comparison with pre-connection and post-connection strategy regarding national electrification plan needs to be revised and rethought for future development and growth of this sector.
\end{abstract}

Keywords: Small hydropower, Electromechanical, Electricity, Vibration, Micro hydropower

\section{Introduction}

Nepal is a mountainous land-locked country with more than 6000 rivers, and small rivers and rivulets having total length more than 45,000 $\mathrm{km}$ [1]. Major source of electricity in Nepal is hydropower as Nepal has estimated theoretical potential 83000 MW capacity and technoeconomically feasible $45610 \mathrm{MW}$ potential [2].However, only $2 \%$ has been harnessed till date which leads to severe and long-lasting electricity crisis. The electricity demand for fiscal year 2016/17 was $1444.06 \mathrm{MW}$ whereas the total production was only $961.2 \mathrm{MW}$ i.e. there is a gap of 482.9 MW between supply and demand, to fulfill which Nepal has been importing an average of $250 \mathrm{MW}$ electricity from India [3]. Almost $43.9 \%$ of total population of Nepal is still deprived of electricity. Only $51.5 \%$ of rural areas, where about $83 \%$ of the total population resides, has been electrified so far [4]. In the current scenario, extension of national grid to non-electrified rural regions is highly unlikely [5]. One of the main causes of this situation despite Nepal's huge hydroelectricity potential is topography of Nepal, lack of development of road transportation and development rate of Nepal. Nepal possess in-country capacity of developing medium-sized hydropower potential of $50 \mathrm{MW}$ [6]. Such hydropower is one of the most cost-effective solution to the existing problem of lack of electricity in rural areas of Nepal. There are almost 3300 micro hydro projects, having capacity less than $100 \mathrm{~kW}$, installed in Nepal that play a major role in rural electrification [7]. Small/Micro hydropower technology is robust and can have life of almost 50 years with low maintenance cost [8], but small/micro hydropower plants in Nepal do not last long. This shows that there is a problem in off-grid policy of Nepal and this study intends to identify the problem through a case study of Giringdi hydropower in specifically electro-mechanical section.

\section{Methodology}

The methodology adopted for this study can be seen in Figure 1. First step of the study was desk study or literature review. In this phase of the study, relevant literature was collected and reviewed related to the small hydropower. It also helped in the identification of site. After identification of site, field data was collected 
through observation, interviews and on-site experiment of vibration. Then, the obtained results were analyzed and finally conclusions were drawn. The detail approach has been mentioned in block diagram.

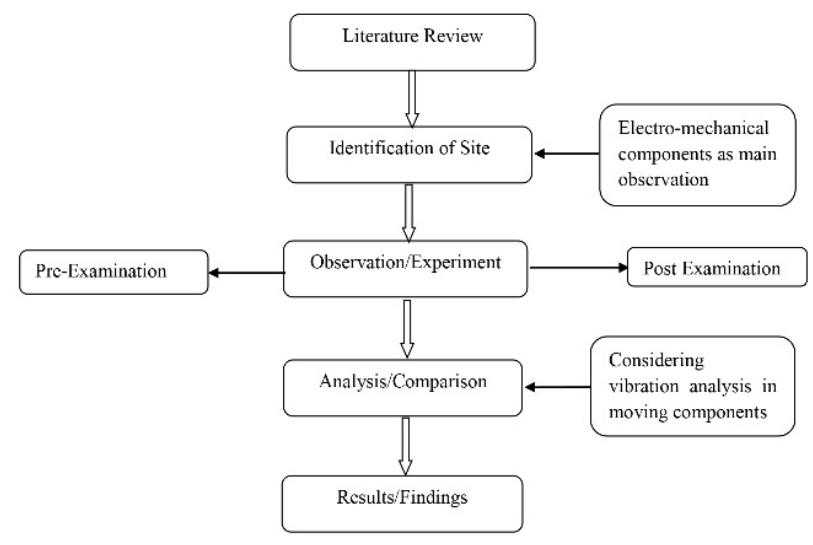

Figure 1: Methodology flow diagram

\subsection{Vibration Testing Equipment}

Vibration Testing was done using Fluke 810 Vibration Tester. The specifications for sensor and tachometer can be seen in Table 1 and Table 2 respectively. The details of testing procedure are mentioned in the user manual of 810 vibration tester [9].

Table 1: Sensor Specifications

\begin{tabular}{|c|c|c|}
\hline Sensor Type & \multicolumn{2}{|c|}{ Accelerometer } \\
\hline Sensitivity & \multicolumn{2}{|c|}{$100 \mathrm{mV} / \mathrm{g}\left( \pm 5 \%, 25^{\circ} \mathrm{C}\right)$} \\
\hline Acceleration Range & \multicolumn{2}{|c|}{80 g peak } \\
\hline Amplitude Nonlinearity & \multicolumn{2}{|l|}{$1 \%$} \\
\hline \multirow{2}{*}{ Frequency Response } & Z & $2-7,000 \mathrm{~Hz} \pm 3 \mathrm{~dB}$ \\
\hline & $\mathrm{X}, \mathrm{Y}$ & $2-5,000 \mathrm{~Hz} \pm 3 \mathrm{~dB}$ \\
\hline Sensing Element Design & \multicolumn{2}{|c|}{ PZT ceramic / shear } \\
\hline Mounting & \multicolumn{2}{|c|}{$\begin{array}{l}\text { 10-32 captive socket head } \\
\text { screw, } 2 \text {-pole rare earth } \\
\text { magnet ( } 48 \text { lb pull strength) }\end{array}$} \\
\hline Vibration Limit & \multicolumn{2}{|c|}{$500 \mathrm{~g}$ peak } \\
\hline Shock Limit & \multicolumn{2}{|c|}{$5000 \mathrm{~g}$ peak } \\
\hline $\begin{array}{l}\text { Electromagnetic } \\
\text { Sensitivity, Equivalent g }\end{array}$ & \multicolumn{2}{|c|}{$100 \mu \mathrm{g} /$ gauss } \\
\hline Sealing & \multicolumn{2}{|c|}{ Hermetic } \\
\hline Temperature Range & \multicolumn{2}{|c|}{$\begin{array}{l}-50^{\circ} \mathrm{C} \text { to } 120^{\circ} \mathrm{C}\left(-58^{\circ} \mathrm{F} \text { to }\right. \\
\left.248^{\circ} \mathrm{F}\right) \pm 7 \%\end{array}$} \\
\hline
\end{tabular}

\section{Case Study of Giringdi Hydropower}

\subsection{Background}

Table 2: Tachometer Specifications

\begin{tabular}{|l|l|l|}
\hline Detection & \multicolumn{2}{|l|}{ Laser Diode Class 2} \\
\hline Range & 6.0 to $99,999 \mathrm{rpm}$ \\
\hline \multirow{2}{*}{ Accuracy } & $6.0-5999.9 \mathrm{rpm}$ & $\pm 0.01 \%$ and \pm 1 digit \\
\cline { 2 - 3 } & $5999.9-99999 \mathrm{rpm}$ & $\pm 0.05 \%$ and \pm 1 digit \\
\hline \multirow{2}{*}{ Resolution } & $0.1 \mathrm{rpm}$ \\
\hline Effective Range & $1 \mathrm{~cm}$ to $100 \mathrm{~cm}(0.4$ in to $39.27 \mathrm{in})$ \\
\hline Response Time & 1 second $(>60 \mathrm{rpm})$ \\
\hline
\end{tabular}

Giringdi Khola hydropower plant is a micro hydropower plant of $75 \mathrm{~kW}$ capacity located at Daga Tumdada, Baglung. It was developed with the support of World Bank, UNDP, DDC, VDC and Community people for the Daga Tumdada VDC. It has been in operation since 2065. The salient features of the plant are mentioned in Table 3.

Table 3: Salient Features of Giringdi Khola hydropower plant

\begin{tabular}{|l|l|}
\hline Specifications & Value \\
\hline Design Discharge & 365 liters per second \\
\hline Gross Head & $43 \mathrm{~m}$ \\
\hline Beneficiary Households & 743 \\
\hline Penstock Length & $98 \mathrm{~m}$ \\
\hline Penstock cross-section & $\begin{array}{l}350 \text { mm diameter with } 3.5 \mathrm{~mm} \\
\text { thickness }\end{array}$ \\
\hline Turbine type & T15 Cross flow \\
\hline Canal length & $1572 \mathrm{~m}$ \\
\hline Generator Type & $\begin{array}{l}160 \mathrm{kVA} \text { KEL Brushless } \\
\text { Synchronous }\end{array}$ \\
\hline Capacity & $75 \mathrm{~kW}$ \\
\hline Connection & Off-grid \\
\hline Ownership & Community based \\
\hline
\end{tabular}

\subsection{Result and Discussions}

\subsubsection{Data from Personal Interviews and Questionnaire}

General data of the plant components, frequency of maintenance, problems encountered, etc. has been collected with the help of questionnaires and personal interviews of the field technicians. It was found that only turbine and ELC used were manufactured by Nepal and all other components like generator, control valves, panel board, bearings, couplings, etc. were manufactured by India. Similarly, breakdown maintenance was practiced on the site. Mainly problems faced were related to the electro-mechanical components. In mechanical 
components, major problems faced were related to the bearings, the bearings had to be replaced three times a year in average. Similarly, the turbine and the couplings had to be replaced once a year. In electrical parts, major problems faced were related to ELC failure, ELC had to be replaced two times in a year on average. Similarly, the panel board has been repaired three times till date. Another major problem faced by the local technicians was lack of expertise in repair and maintenance of electronic parts, for the repair and maintenance of electronic parts, experts from outside were required.

\subsubsection{Data collected from Vibration testing of components}

Vibration Testing was done on the turbine, before and after coupling and generator. Testing was done in two different conditions. First the testing was done when the plant faced mechanical problems and secondly, testing was again done after the plant was repaired.
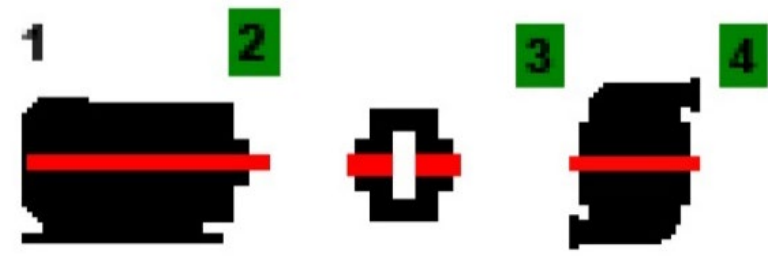

Figure 2: Diagram indicating different testing locations

Location 1 is the end of generator and Location 2 represents the connection of one end of belt drive and generator, Location 3 indicates the connection of other end of belt drive and turbine, Location 2 and 3 together represent the belt driven connection and Location 4 indicate the free end of turbine. Location 1 was taken as reference by the testing equipment and the rpm varied from 975 to 1000 .

The graph of the vibration data for axial direction of Location 2 before and after repair can be seen in the Figure 3 and Figure 4 respectively. The vibration for premaintenance seems to be more destructive than post maintenance one with high level of noise per cycle. The number of events per revolution (order) goes on increasing with time.

Similarly, the graph of the vibration data for tangential direction of Location 2 before and after repair can be seen in the Figure 5 and Figure 6 respectively. The graphs show the similar difference before and after maintenance work as seen above. The graph behavior for pre-post maintenance for other location say 3 and 4 seem to be quite less noisy than previous one though the number of events per revolution is not so less.

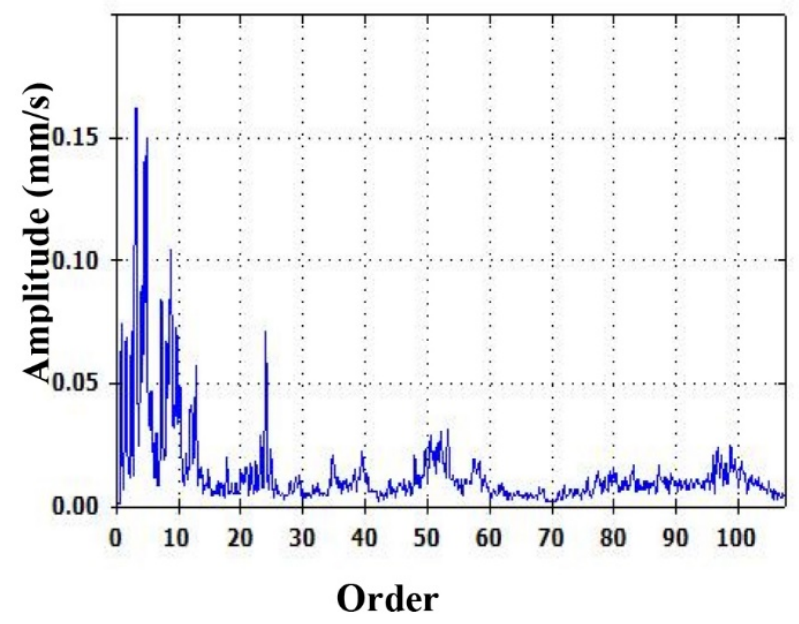

Figure 3: Vibration graph for axial direction of Location 2 (before maintenance)

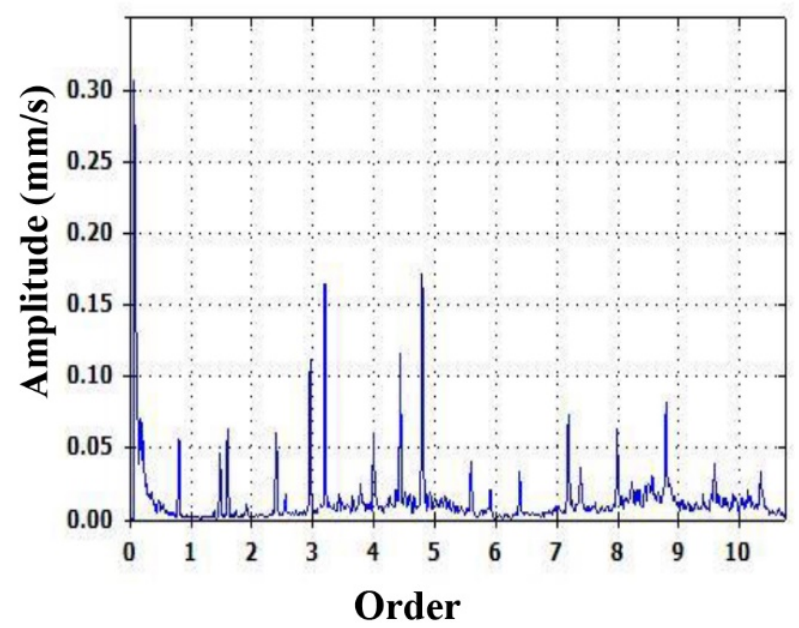

Figure 4: Vibration graph for axial direction of Location 2 (after maintenance)

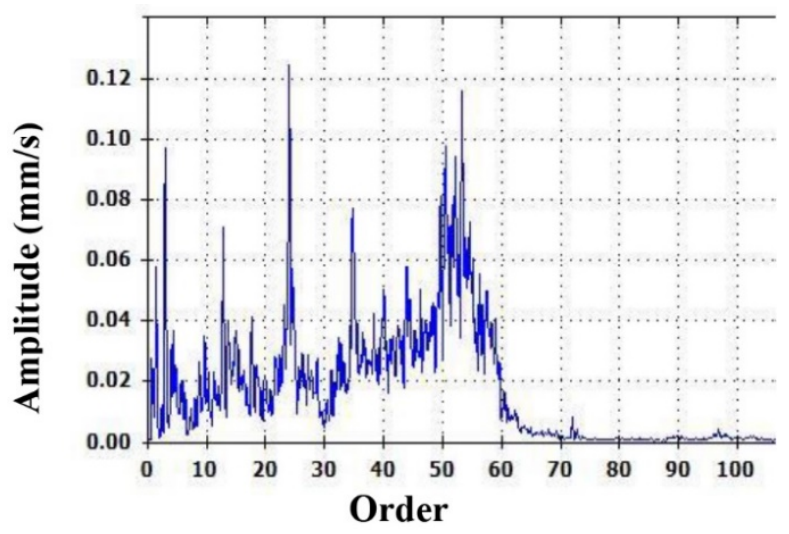

Figure 5: Vibration graph for tangential direction of Location 2 (before maintenance)

And, also in the graph of the vibration data for radial direction of Location 2 before and after repair can be seen in the Figure 7 and Figure 8 respectively. 


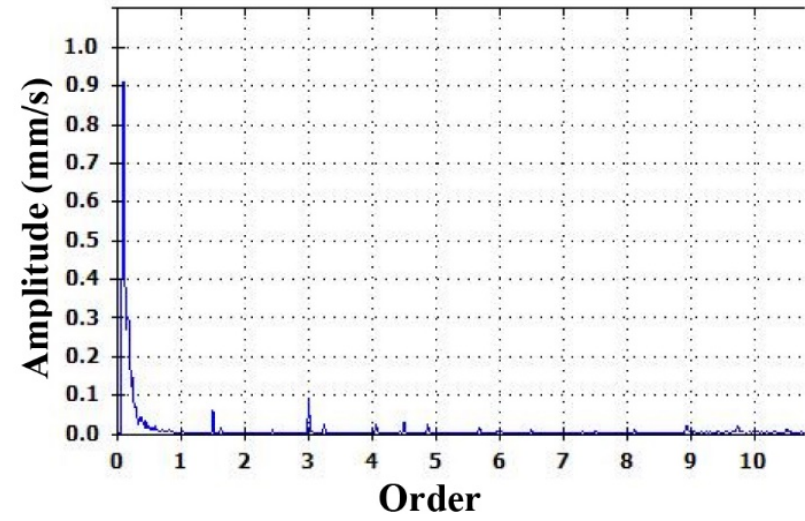

Figure 6: Vibration graph for tangential direction of Location 2 (after maintenance)

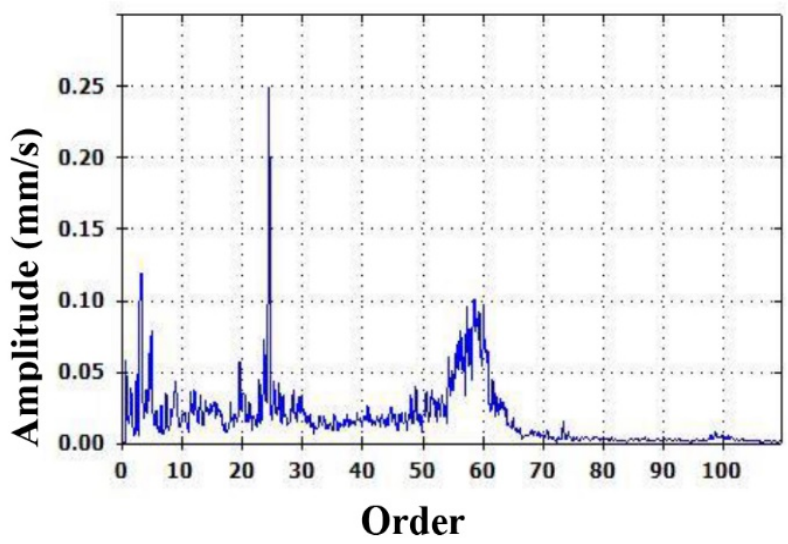

Figure 7: Vibration graph for radial direction of Location 2 (before maintenance)

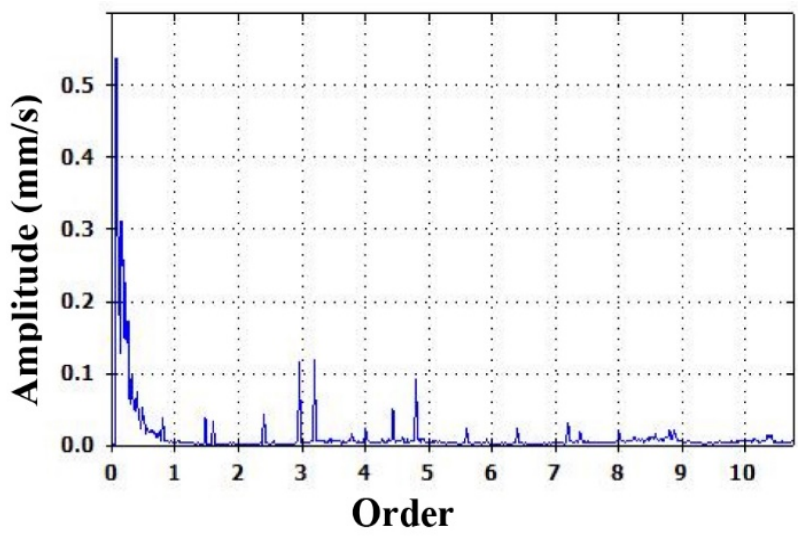

Figure 8: Vibration graph for radial direction of Location 2 (after maintenance)

The graph of the vibration data for axial direction of Location 3 before and after repair can be seen in the Figure 9 and Figure 10 respectively.

The graph of the vibration data for tangential direction of Location 3 before and after repair can be seen in the Figure 11 and Figure 12 respectively.

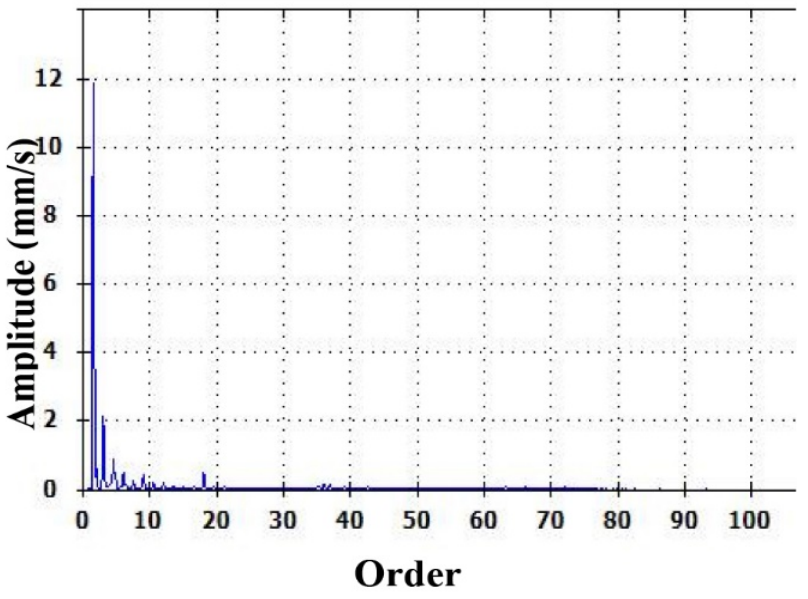

Figure 9: Vibration graph for axial direction of Location 3 (before maintenance)

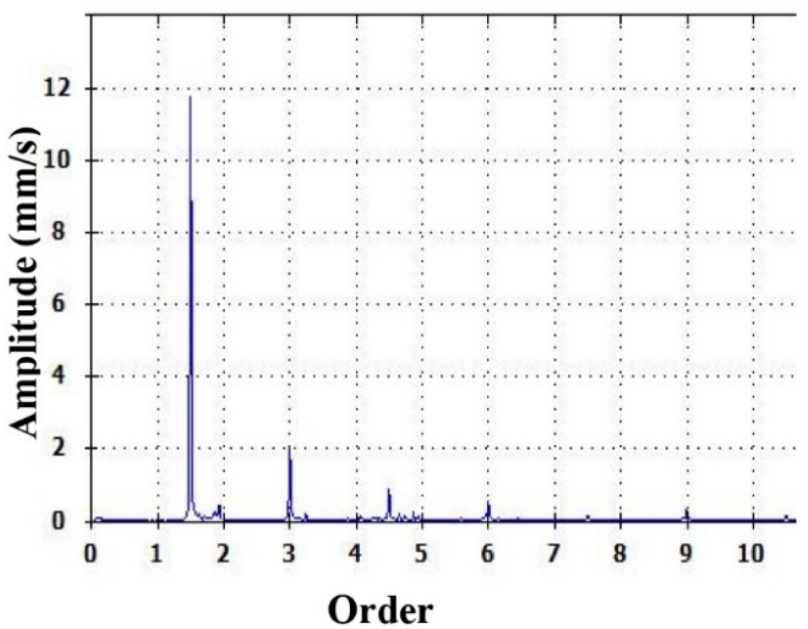

Figure 10: Vibration graph for axial direction of Location 3 (after maintenance)

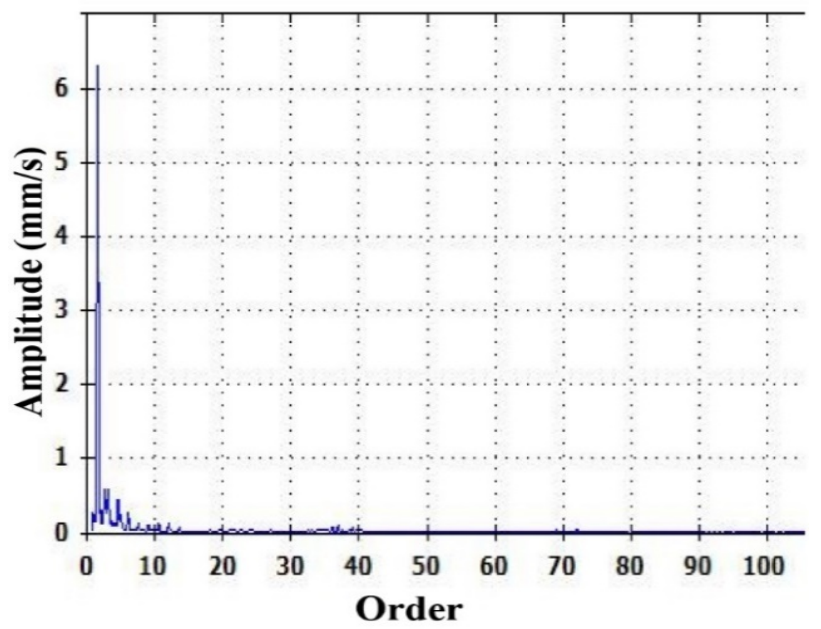

Figure 11: Vibration graph for tangential direction of Location 3 (before maintenance)

The graph of the vibration data for radial direction of Location 3 before and after repair can be seen in the Figure 13 and Figure 14 respectively. 


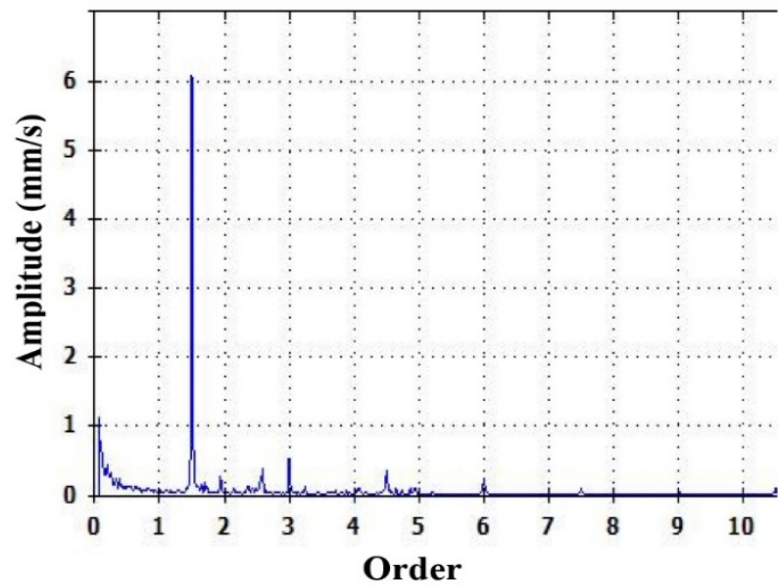

Figure 12: Vibration graph for tangential direction of Location 3 (after maintenance)

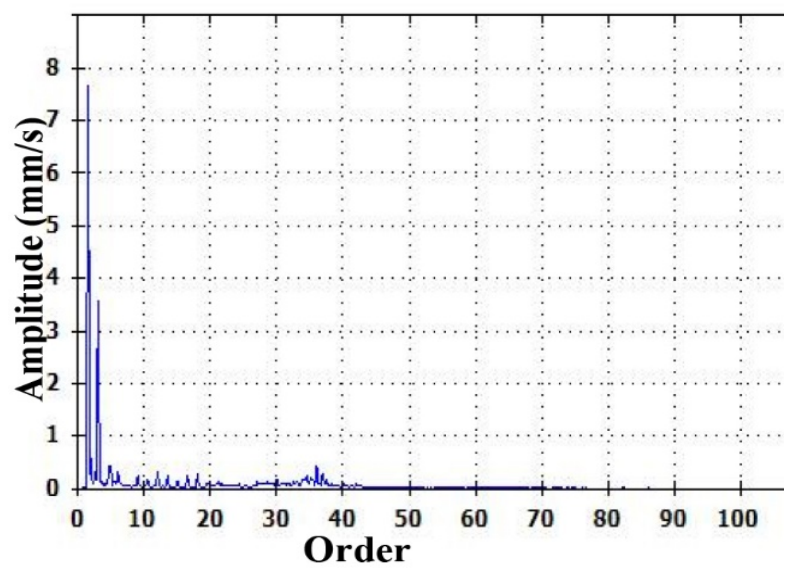

Figure 13: Vibration graph for radial direction of Location 3 (before maintenance)

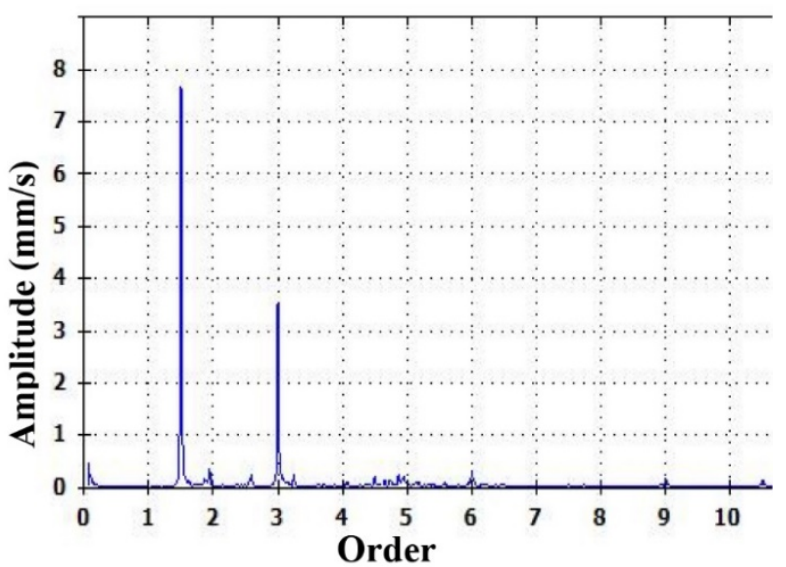

Figure 14: Vibration graph for radial direction of Location 3 (after maintenance)

The graph of the vibration data for axial direction of Location 4 before and after repair can be seen in the Figure 15 and Figure 16 respectively. The graph of the vibration data for tangential direction of Location 4 before and after repair can be seen in the Figure 17 and Figure 18 respectively.

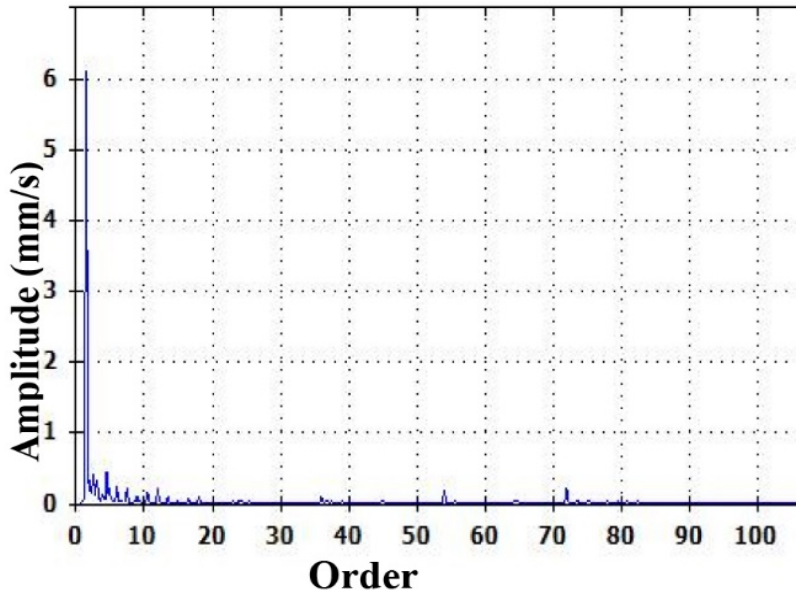

Figure 15: Vibration graph for axial direction of Location 4 (before maintenance)

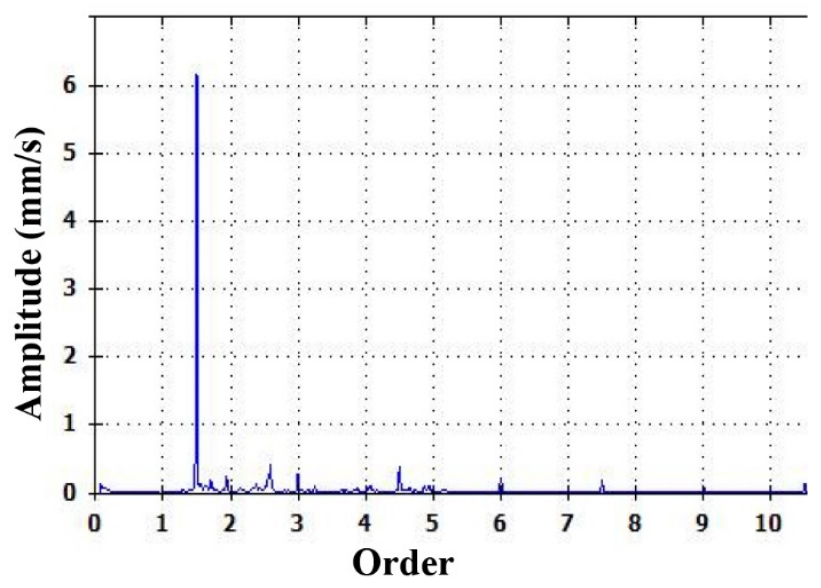

Figure 16: Vibration graph for axial direction of Location 4 (after maintenance)

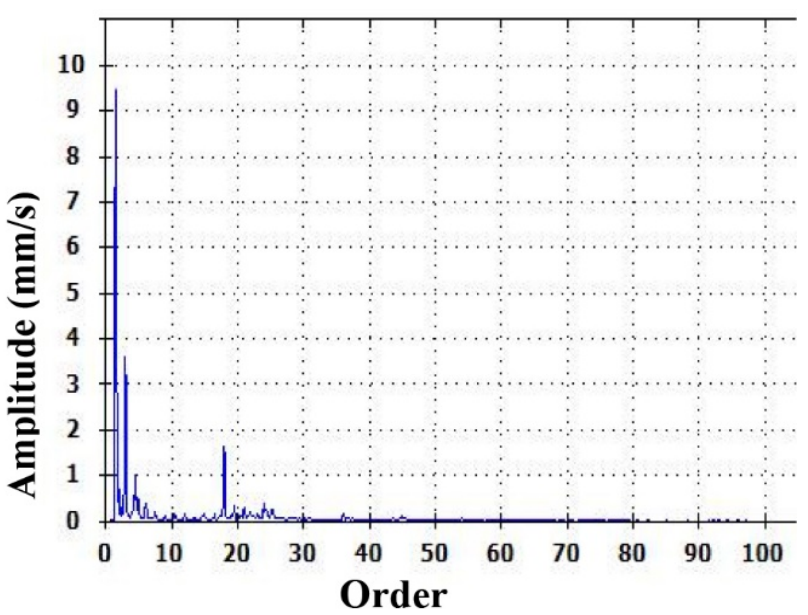

Figure 17: Vibration graph for tangential direction of Location 4 (before maintenance)

The graph of the vibration data for radial direction of Location 4 before and after repair can be seen in the Figure 19 and Figure 20 respectively. 


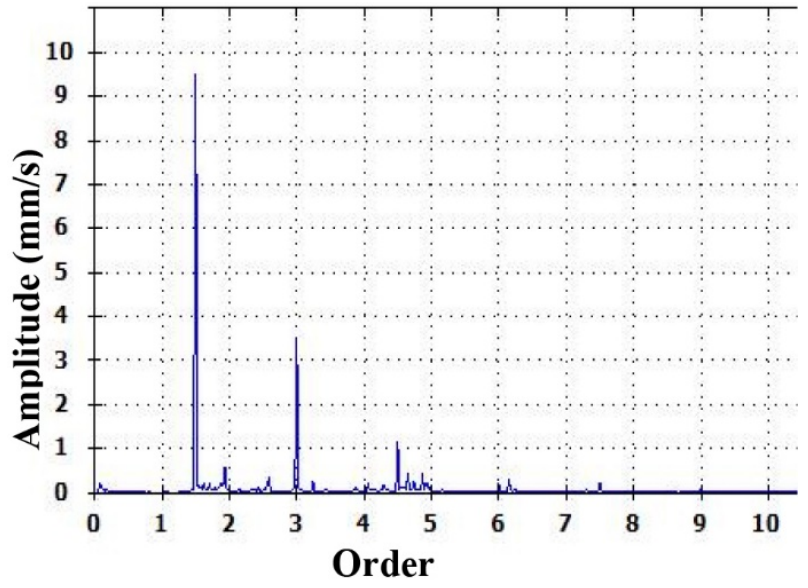

Figure 18: Vibration graph for tangential direction of Location 4 (after maintenance)

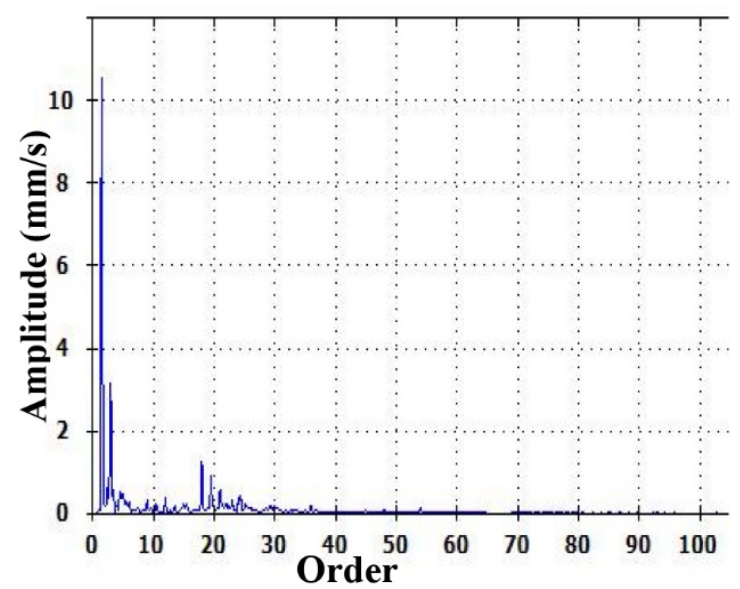

Figure 19: Vibration graph for radial direction of Location 4 (before maintenance)

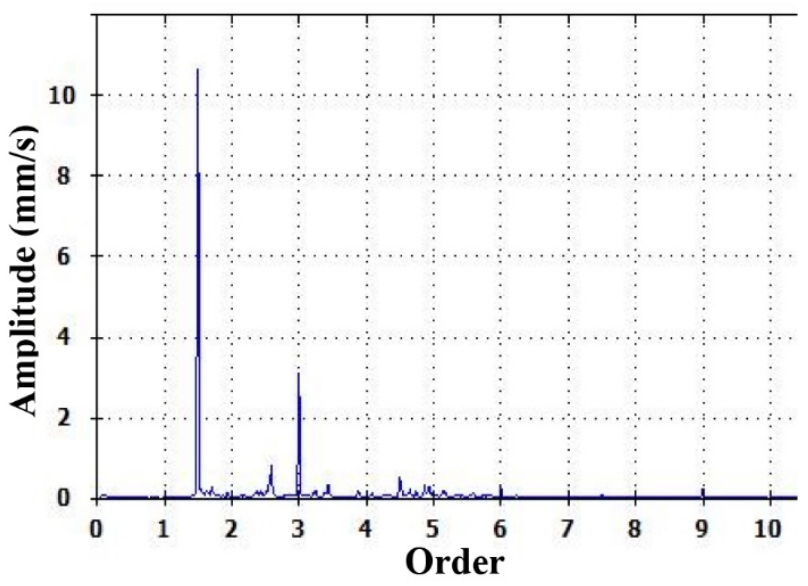

Figure 20: Vibration graph for radial direction of Location 4 (after maintenance)

\subsubsection{Data Analysis and Discussions}

From the analysis along all the electro-mechanical components in the station, the major issues were found in the moving section than the other stationary electronic and mechanical parts. It is the reason we chose the detail study for moving parts from turbine shaft to the generator in three directions/planes $\mathrm{X}-\mathrm{X}, \mathrm{Y}-\mathrm{Y}$ and $\mathrm{Z}-\mathrm{Z}$ with the magnetic sensor which gives the data in amplitude $(\mathrm{mm} / \mathrm{s})$ and the order.

Generally, order of one to two times can be caused by looseness, misalignment, bent shaft and imbalance. First two or three distinctive harmonics indicate the misalignment, looseness of bearing, fault in bearings and bent shaft [10]. From the data of pre-maintenance shown above, it can be observed that the plant had fault in bearings looseness and misalignment of turbine shaft. The data also indicates some non-standard problems experienced by the plant. The problem in bearing was arising due to the chain effect of failure. Erosion of turbine leads to eccentricity in rotation of turbine, which lead to shaft misalignment and which ultimately lead to problems in bearings. This is also validated by the data seen above as location 2 (end of generator shaft) showed higher amplitude vibration in comparison to location 4 (turbine). While inspection too, bearing clearance problem was found and the problem was solved by the local technicians, bearings also had to be replaced. From analysis, it was seen that bearing at location 2 was comparatively more damaged than location 3 . After maintenance, data was again taken and it seemed that the chain effect of failure caused misalignment of shaft. This indicates that not only bearings were flawed, but there were problems in shaft alignment and turbine rotation. Preventive maintenance could have prevented the chain effect seen above. The main cause of this problem could be the breakdown maintenance practiced in Nepal.

The major problems faced by Giringdi hydropower plant were related to the electro-mechanical components. In mechanical components, problems generally arise in moving components and the problems mentioned above are not only limited to Giringdi but are common for almost all micro/small hydropower plants. Almost all micro/small hydropower plants face similar problems as illustrated in the case study of Giringdi. The major cause of this problem is a) the breakdown maintenance practiced almost exclusively in all off-grid connections and b) lack of standardization and testing practices of components of hydropower.

\section{Conclusions and Recommendations}

Hence, a case study on Giringdi hydropower has been successfully conducted in close coordination of local technicians. The basic problem observed was mainly in the stationary and moving parts of electromechanical components. The observed components were ELC, heater, 
valves, etc. as stationery and turbine, generator, shaft, bearing as moving one. The main reason for the breakdown of such station, particularly Giringdi is lack of preventive maintenance in regular schedule, insufficient technical manpower, and lack of knowledge, weak policy in off grid/not connected area, lack of standardization of components and lack of testing of components.

A small problem in one moving part say turbine (erosion of turbine) starts the chain effect resulting ultimately in overheating and problems in generator, which changes a small problem to breakdown of the whole system. The breakdown of whole system requires maintenance of high cost and highly skilled manpower and also results in halt of system for long time.

Off grid/not connected system or the isolated connection system can be a good approach for any government to connect the people of all topography for overall development, especially for Nepal because of its uneven topography (Terai, Hilly and Himalayan). But, the policies for such system need to be well checked for proper execution. Such policies need to come with other mandatory sub-policies like national guidelines and rules for repair and maintenance schedule, level of skilled manpower requirement, technical component specifications and standards. So, for the better implementation and sustainability of micro/small hydropower, the policies and sub-policies should not only be developed to increase the number of SHPs but also be developed considering the problems encountered during operation of small/micro hydropower.

\section{Acknowledgments}

The authors are indebted to the whole team of Nepal Academy of Science and Technology (NAST) without whom the study would not have been possible. The authors are especially grateful to the team of Giringdi hydropower for their help and support during data collection and field visit.

\section{References}

[1] R. H. Sharma and R. Awal, "Hydropower development in Nepal,” Renew. Sustain. Energy Rev., vol. 21, pp. 684-693, 2013.

[2] “Observed Climate Trend Analysis of Nepal," Kathmandu, 2017.

[3] "A Year in Review. Nepal Electricity Authority," Kathmandu, 2018.
[4] S. Uprety, B. Mainali, S. Raj, and R. Prasad, "Framework to assess sustainability of micro-hydro projects in the Operation Phase," vol. 8914, pp. 637-644, 2017.

[5] S. K.C., S. K. Khanal, P. Shrestha, and B. Lamsal, "Current status of renewable energy in Nepal: Opportunities and challenges," Renew. Sustain. Energy Rev., vol. 15, no. 8, pp. 4107-4117, Oct. 2011.

[6] N. P. Chaudhary and R. Dhital, "Micro \& Mini Hydro Based Mini-Grid for Rural Energy Access in Taplejung, Nepal," IOE Grad. Conf., pp. 71-83, 2016.

[7] P. N. Ranjitkar, "The Scenario of Microhydro Development in Nepal," The Nepal Weekly, 2014. .

[8] O. Paish, "Small hydro power: Technology and current status," Renew. Sustain. Energy Rev., vol. 6, no. 6, pp. 537$556,2002$.

[9] “User Manual Fluke 810 Vibration Tester,” 2010.

[10] J. L. Taylor, The Vibration Analysis Handbook. VCI, 2003. 